\title{
MECHANISMS FOR THE BIODEHALOGENATION OF IODOCOMPOUNDS
}

J. E. SINSHEIMER*, T. WANG ${ }^{+}$, S. RÖDER, Y. Y. SHUM

College of Pharmacy, University of Michigan

Ann Arbor, Michigan 48109

\section{Received May 8,1978}

SUMMARY: The in vitro deiodination of $\left[{ }^{125} I\right]-4$-iodobiphenyl, [ ${ }^{125}$ I]-4iodonitrobenzene and $\left[{ }^{125}\right.$ I]-4-iodoaniline was investigated. No deiodination was detected in rat thyroid homogenates. However, at least three biodeiodination mechanisms were indicated for substrates in rat liver subcellar fractions. Microsomal dehalogenation occurred to a minor extent with increased dehalogenation taking place in the cytosol fraction. The cytosol deiodination was extensive for 4-iodonitrobenzene and was mediated by glutathione. A second cytosol deiodination mechanism, not mediated by glutgthione, was evident when 4-iodobiphenyl was the substrate. This soluble enzyme system could be enhanced by Arochlor 1254 or 4-iodobiphenyl pretreatment.

INTRODUCTION: Iodinated organic compounds are used as positive X-ray contrast materials (1) and are becoming broadly employed as diagnostic, scanning and radiopharmaceutical agents (2). While there is only limited knowledge as to the metabolism of such compounds, it has been recognized for some time that deiodination can occur with subsequent elevated serum (3), thyroid (4) and urine (5) iodide levels.

The metabolism of $\left[{ }^{125} I\right]-4$-iodobipheny] has been used in our laboratories as a model for in vivo biodeiodination studies (6). These studies indicate that 7 to $8 \%$ of the original dose appears as inorganic iodide in the urine. It is the purpose of this paper to describe our invitro experiments as to the mechanisms of the biodeiodination of 4-iodobiphenyl and other model compounds.

\section{MATERIALS AND METHODS}

Substrates: $\quad\left[{ }^{125}\right.$ I]-4-Iodobiphenyl was obtained by an exchange reaction of 4-iodobiphenyl ( $183 \mathrm{mg}$ ) with $\left[{ }^{125} \mathrm{I}\right]$-sodium iodide $(2.5 \mathrm{mCi})$ in ethylene glycol $(6 \mathrm{ml})$ at $140^{\circ} \mathrm{C}$ for 24 hours.

*To whom correspondence should be addressed.

Abbreviations: PCB, polychlorinated biphenyl (Arochlor 1254); GSH, reduced gluthathione.

National Science Foundation Undergraduate Research Participant under Grant SMI 76-03634. 
The product was extracted with benzene from the reaction mixture after the addition of water $(6 \mathrm{ml})$ and recrystallized to constant specific activity (9.0 $\mu \mathrm{Ci}$ per mg) in methanol. Radiochemical purity of the final product (144 mg) was established in two TLC systems and reverse isotopic dilution indicated a purity of 99.7\%. [125I]-4-Iodonitrobenzene was obtained in a similar manner with the exchange reaction at $190^{\circ} \mathrm{C}$ for 12 hours followed by extraction with $\mathrm{CHCl}_{3}$ and recrystallization to constant specific activity $(1.0 \mu \mathrm{Ci}$ per mg) with $\mathrm{CCl}_{4}$. Radiochemical purity was established in two TLC systems and reverse isotopic dilution indicated 97.98 purity.

[125I]-4-Iodoaniline $\left(0.23 \mu \mathrm{Ci}\right.$ per mg) was labeled at $80^{\circ} \mathrm{C}$ for 48 hours followed by extraction with ether and recrystallization three times from heptane. TLC in two systems gave single spots.

Liver Preparations: Male rats (Sprague Dawley 200 to $250 \mathrm{~g}$ ) were killed in an ether chamber and the livers perfused with $1.15 \% \mathrm{KCl}(200 \mathrm{ml})$ before excision and homogenation in an equal volume of $\mathrm{pH} 7.4$ phosphate buffer with a Tekmer Tissumizer in a cold room at $10^{\circ} \mathrm{C}$. Homogenates were centrifuged at $9000 \mathrm{~g}$ for 30 minutes and the supernatant centrifuged $(100,000 \mathrm{~g}, 1 \mathrm{hr})$. The separated microsomal pellet was suspended in pH 7.4 phosphate buffer before both supernatant (cytosol) fractions and microsomal suspensions were recentrifuged $(100,000$ $\mathrm{g}, 1 \mathrm{hr}$ ). The washing and centrifugation were repeated before the microsomal pellet was reconstituted in $\mathrm{pH} 7.4$ phosphate buffer in a volume equal to the original homogenate.

Dialysis of Cytosol: Cell supernatant fractions prepared as above were divided into two portions. One portion was transferred into a 20-ml capped glass vial as a control and the other portion into a dialysis membrane. Solutions were immersed in distilled water $(1000 \mathrm{ml})$ for 18 hours at $10^{\circ} \mathrm{C}$ with constant stirring. Precipitates from the dialysed fractions were removed by centrifugation $(2000 \mathrm{~g}$, $30 \mathrm{~min}$ ).

Thyroid Preparations: Thyroid glands from five rats were pooled and homogenized in 3 volumes of $\mathrm{pH} 7.4$ phosphate buffer in a glass homogenizer. The homogenates were centrifuged $(2000 \mathrm{~g}, 30 \mathrm{~min})$ and the supernatant was used without further processing.

Pretreatment Studies: Rats were injected ip with either a single dose of Arochlor $1254(300 \mathrm{mg} / \mathrm{Kg}$ in $0.5 \mathrm{ml}$ of peanut oil) 4-iodobiphenyl (100 mg/Kg) or peanut oil. At the end of the third day liver homogenate fractions were prepared as described previously.

Incubation: Mixtures of $20 \mu \mathrm{l}$ of an ethanol solution containing 40,000 cpm of one of the following substrates, [125I]-4-iodobiphenyl, [125I]-4-iodonitrobenzene or [125I]-4-iodoaniline, $460 \mu \mathrm{l}$ of enzyme preparations and $20 \mu 1$ of additive solutions were incubated at $37^{\circ} \mathrm{C}$ for 2 hours. The following enzyme preparations and phosphate buffer ( $\mathrm{pH} 7.4)$ additive solutions were used: A) the microsomal fraction with buffer containing $\mathrm{MgCl}_{2}$ (15 $\mu$ mole), nicotinamide (20 $\mu$ mole) and NADPH (0.05 $\mu$ mole); B) cytosol and buffer without additives; C) cytosol and buffer containing GSH (2 to $3 \mathrm{mg})$; D) dialysed cytosol and buffer without additives; E) dialysed cytosol and buffer containing GSH (2 to $3 \mathrm{mg}$ ). Analytical Procedure: To stop the incubation, 208 trichloracetic acid (150 $\mu 1)$ was added to each sample immediately after it was removed from the water bath. The supernatant was removed after centrifugation (1700 $\mathrm{g}, 15 \mathrm{~min})$, and filtered into a disposable culture tube. The pellet was washed with $0.5 \mathrm{ml}$ of phosphate buffer and the supernatant wash, which was separated again by centrifugation, was combined with the first supernatant. The entire supernatant was spotted on a $4 \mathrm{~cm}$ wide paper strip (Whatman \#3MM paper) and developed by descending method for $50 \mathrm{~cm}$ with $\mathrm{n}$-butyl alcohol : $0.5 \mathrm{M} \mathrm{NH} 4 \mathrm{OH}$ : ethanol : water (20:20:2:1) (7). The paper was cut into $1 \mathrm{~cm}$ strips to be counted for construction of a chromatogram. 
homogenates showed deiodination occurred, a comparison of incubation under high and low oxygen tensions did not indicate that anaerobic dehalogenation was an important pathway for the compound as had been reported for halothane (8) and DDT (9). Our in vivo studies after the administration of $\left[{ }^{125} I\right]-4-i o d o b i p h e n y 1$ to rats indicated the accumulation of $\left[{ }^{125} I\right]$ in the thyroids of these animals (6). However, in the present study incubations of $\left[{ }^{125} I\right]-4-i o d o b i p h e n y l$ in $2000 \mathrm{~g}$ thyroid tissue homogenates did not show deiodination to occur in such homogenates. Therefore, the accumulation of $\left[{ }^{125} \mathrm{I}\right]$ in thyroid is assumed to occur primarily following liver deiodination and not directly in the thyroid. The deiodinations occurring with $\left[{ }^{125} I\right]-4-i o d o b i p h e n y l,\left[^{125} I\right]-4-i o d o-$ nitrobenzene or $\left[{ }^{125} \mathrm{I}\right]-4-i o d o a n i l i n e$ in liver homogenates were followed more extensively. Trichloracetic acid precipitation of these incubations followed by partition paper chromatography (7) and gamma counting were used to detect inorganic iodide. This proved to be a suitable method to detect small amounts of [125I] in the presence of the large residual radioactivity due to nontransformed substrates. With standard solutions in zero-time control incubations, 99.68 of $\left[{ }^{125} I\right]-4-i o d o b i p h e n y l$ was precipitated and removed along with acid-denatured protein. Under these conditions there was a loss of only 68 of added [125I]. Paper chromatography then efficiently separated the $\left[{ }^{125} I\right]$ from the remaining [ ${ }^{125}$ I]-4-iodobiphenyl prior to counting. Similar results were observed for the other two substrates.

our in vivo experiments with iodobiphenyl administered in three doses at 4-day intervals indicated a self induction of its own metabolism which included increased yields of inorganic iodide. Therefore, transformation in normal liver homogenates were also compared to those occurring in liver homogenates obtained from rats pretreated with iodobiphenyl or with Arochlor 1254. The extent of deiodination in the microsomal and cytosol fractions, as well as the importance of GSH conjugation in deiodination was examined for the three $\left[{ }^{125}\right.$ I] labeled substrates. Results of these studies are listed in Table 1. The relatively high control values for iodoaniline for both the microsomal 
TABLE 1

Deiodination in liver microsomal and cytosol fractions

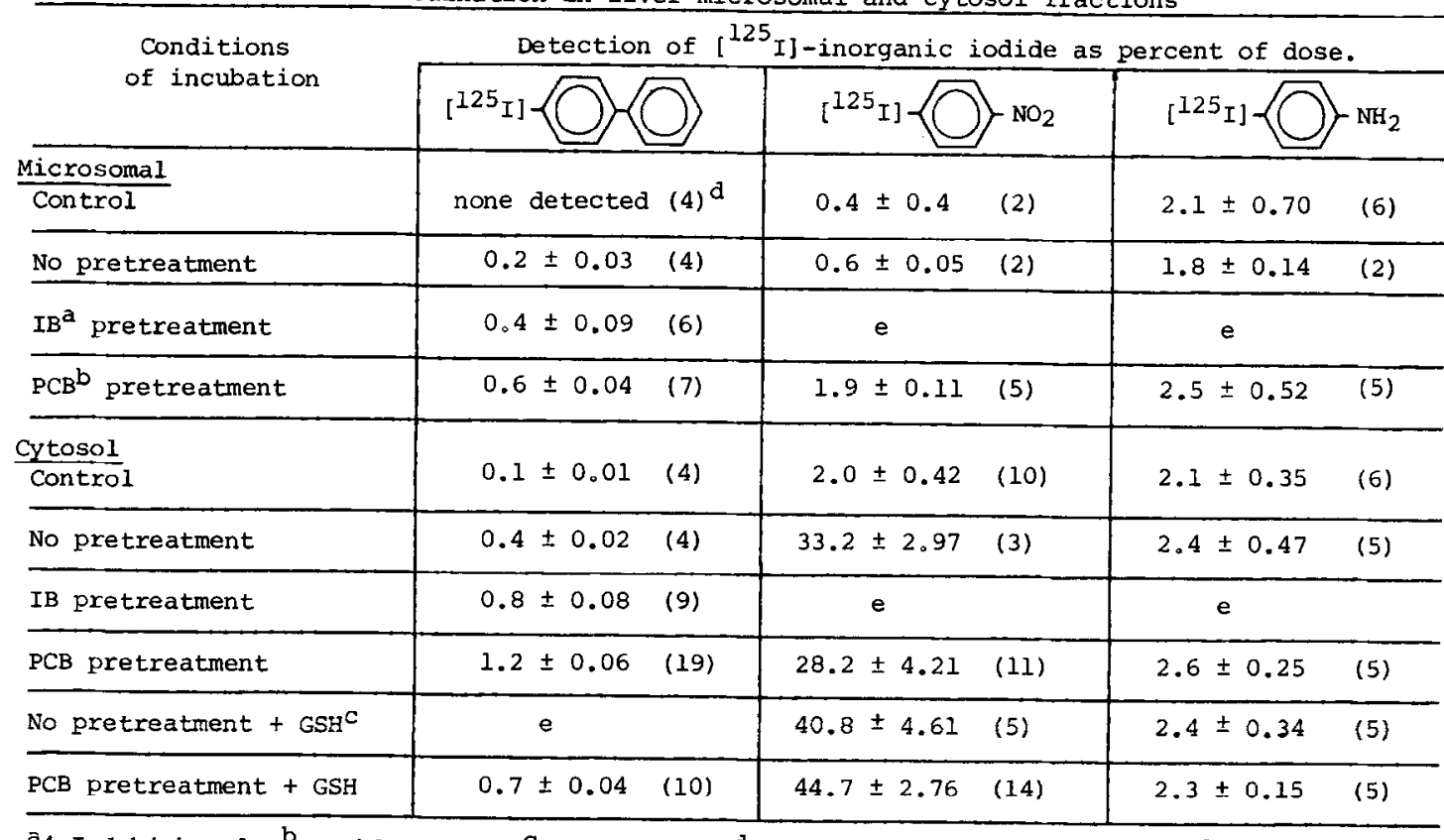

$a_{4-I o d o b i p h e n y 1, ~} b_{\text {Arochlor }} 1254, c_{\text {glutathione, }} d_{\text {number }}$ of determinations, and $e_{\text {not }}$ determined.

and cytosol fractions demonstrated spontaneous non-enzymatic deiodination for this compound to be important. However, enzymatic dehalogenation could not be established on a statistically significant basis for any of the experimental conditions applied to iodoaniline.

Under the same conditions no spontaneous deiodination could be detected for iodobiphenyl and a low level of deiodination was found for the microsomal fractions from normal animals. There was a statistically significant increase in yield of iodide in liver microsomal preparations from iodobiphenyl or PCB pretreated animals $(\mathrm{p}<0.005$ and $\mathrm{p}<0.0005$ respectively) as compared to those from normal animals. Deiodination of iodobiphenyl was even greater in the cytosol fraction. It is of interest that pretreatment with either iodobiphenyl or PCB resulted in an increase in iodide yield over normal liver preparations $(p<0.0005)$. It is also noteworthy that there was a significant $(p<0.0005)$ reduction of iodide yield with the addition of GSH to the cytosol incubation from the $\mathrm{PCB}$ pretreated animals. 


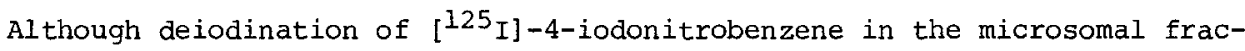
tion of non-pretreated rats was slightly in excess of the control, this increase was not statistically significant due to the large variations of the control sample. Microsomal enzymatic activity, however, was established and was increased $(p<0.05)$ by PCB pretreatment.

In the cytosol fraction, deiodination of $[125 \mathrm{I}]-4$-iodonitrobenzene was found to be much higher even prior to chemical pretreatment. PCB pretreatment of rats in this case did not result in a statistically significant difference in yield of iodide. Addition of GSH to the post-microsomal fraction from rats with or without $P C B$ pretreatment increased the extent of deiodination.

Pretreatment results showed good agreement with the established ability of PCB to induce microsomal enzymatic activity. While PCB stimulation of enzymatic activity in the post-microsomal fraction is not as well established, our results in the present study of [125I]-4-iodobiphenyl dciodination in this fraction show an increased yield of deiodination. It would be of interest to investigate whether enzyme induction is responsible for the increased yield.

In the past enzymatic dehalogenation in the post-microsomal fraction has been related to GSH conjugation. Removal of hepatic GSH content by dialysis of liver soluble enzyme preparations prior to incubation has been shown to impede this reaction (10). The reaction can be restored by the addition of GSH. In the present experiment, results of [125I]-4-iodobiphenyl indicated that addition of GSH to the PCB pretreated post-microsomal fraction actually lowered the extent of deiodination. These experiments were confirmed by dialysis studies with and without the readdition of GSH.

Kraus (11) also observed the inhibitory effect of excess added glutathione to the dechlorination of $\alpha$-hexachlorocyclohexane. This study with $\alpha$-hexachlorocyclohexane and the present investigation indicates the presence of two dehalogenating enzymes in the hepatic cytosol. One is GSH dependent, leading to dehalo. genation and conjugation, while the other is inhibitad by GSH. 


\section{ACTONOWLEDGEMENTS}

Supported in part by a grant from the University of Michigan Cancer Research Institute.

\section{REFERENCES}

1. Herms, H-J., and Taenzer, V. (1975) Drug Design Vol. VI, Ariens, E.J., Ed., Pp. 262-295, Academic Press, New York.

2. Counsell, R.E. and Ice, R. (1975) Drug Design Vol. VI, Ariens, E.J., Ed., pp. 171-259, Academic Press, New York.

3. Man, E.B. and Peters, J.P. (1950) J. Lab. Clin. Med., 35, 280-283.

4. Slingerland, D. W. (1957) J. Clin. Endocrinol. Metab., 27, 82-93.

5. Keating, F. R., Haines, S. F., Power, M. H., and Williams, M. M. D. (1950) J. Clin. Endocrinol. Metab., 20, 1425-1464.

6. Shum, Y. Y. (1977) Ph.D. Thesis, University of Michigan, Ann Arbor.

7. Grasbeck, R., Lamberg, B. A., and Bjorksten (1960) Acta Endocrinol., 34, 113-120.

8. Van Dyke, R. A., and Gandolfi, A. J. (1976) Drug Metab. Dispos., 4, 40-44.

9. Miskus, R. P., Blair, D. P. and Casida (1965) J. Agric. Food Chem., Z3, 481-483.

10. Combes, B., and Stakelum, G. S. (1961) J. Clin. Invest., 40, 981-988.

11. Kraus, P. (1975) Naunyn-Schmiedeberg's Arch. Pharmacol., 29I, 79-87. 